\title{
TÉRMINOS CIENTÍFICOS Y MATEMÁTICOS EN LA PROSA MORALISTA ESPAÑOLA DEL SIGLO XVIII
}

Los lectores actuales de Emilia Pardo Bazán no tienen dificultades para entender qué es lo que hace cuando, en el capítulo 27 de La tribuna (1882), escribe a propósito del insensible seductor de su heroína: “ $\mathrm{Ha}$ bía llegado Baltasar al mayor número de pulsaciones que determinaba en él la calentura amorosa". Nos decimos que, en su calidad de escritora naturalista, doña Emilia se esfuerza por encontrar términos científicos, o por lo menos tan objetivos como sea posible, para describir el estado emocional de sus personajes. Consideramos su búsqueda de tal exactitud como un intento de incorporar a las letras españolas las prácticas de una escuela literaria francesa, que a su vez se esforzaba por poner a la literatura a la par con el positivismo prevaleciente del siglo XIX. Siendo así, ¿cómo habremos de interpretar la expresión de otro escritor que, casi cien años antes, desaprueba la mentalidad quijotesca de aquellos entusiastas de los asuntos políticos que creen que su gran idea puede convertirse en realidad con sólo desearlo?: “El mejor termómetro para apreciar a los hombres es en todos tiempos ver que se hacen a síjusticia y a los demás, y no juzgarlos por su lenguaje y apariencias; oues el acaloramiento de las pasiones disfrazadas se presenta con el aspecto del celo más ardiente''1.

La explicación más general radica en reconocer la popularidad de la ciencia en la Ilustración española. Las investigaciones insustituibles de Olga Victoria Quiroz Martínez, Jean Sarrailh, Richard Herr y José María López Piñero ya han documentado la manera en que las filosofías y las teorías científicas nuevas entraron en España. Más pertinente para esta exposición es, sin embargo, el reciente estudio de Joaquín Arce. Muestra de qué manera el prestigio y la vitalidad de esas nuevas corrientes hicieron que los poetas, más o menos a partir de 1760 , sintieran la necesidad de elevar la poesía al mismo alto rango, alabando a los grandes pensadores modernos y celebrando en versos sus adelantos $^{2}$. La investigación de Arce da pruebas del hecho de que la

1 JoAQuín Acevedo, Reflexiones político-morales, Juan Alzine, Perpignan, 1800, p. 49. En esta cita, al igual que en las demás, modernizo la ortografia y la puntuación.

${ }^{2} \mathrm{Me}$ refiero a O.V. Quiroz MARTínez, La introducción de la filosofía moderna en Es- 
ciencia y la matemática se estaban dejando sentir en diferentes campos, tan amplia era la influencia de la nueva cultura. En realidad, como lo señala (pp. 298 y 304), barómetro y termómetro eran dos de los términos recomendados por Cadalso en su famosa sátira para que los usaran abundantemente los pretenciosos "eruditos a la violeta" con el fin de mostrar que estaban al día de la última moda intelectual.

Visto así, es casi seguro que el empleo que hace Joaquín Acevedo de "termómetro" en la cita anterior refleja la intromisión, puramente por su novedad, de este vocabulario técnico en el tratamiento de los temas morales. Sin embargo, puede ser que esa posibilidad represente una realidad más complicada de lo que se pudiera creer en un principio. La suposición de modernidad, por ejemplo, debe enfrentarse al hecho de que tanto los filósofos antiguos como los teólogos medievales y renacentistas han escrito sobre el alma, a través de los siglos, en términos geométricos. La concepción del alma situada en el centro del hombre microcósmico engendró un esquema geométrico, a veces de gran complejidad metafórica, de círculos, circunferencias, radios y líneas que se intersectan para dar cuenta de la penetración del alma por el espíritu divino ${ }^{3}$. La suposición de progreso es cuestionada en el ejemplo siguiente, cuando pasamos de la concepción de un centro metafísico a la de un centro físico. Un personaje conservador no menos importante que Juan Pablo Forner se aooya en una analogía del concepto newtoniano de la gravedad para ilustrar su argumento sobre la necesidad de que cada ciudadano trabaje por el mayor bien del país en su conjunto:

Newton dijo que la Atracción es la ley fundamental en que estriba la permanencia y orden del universo. De la tendencia o virtud oculta que inclina todos los seres a buscarse y unirse en un centro común resulta la unidad admirable que se nota en ese gran sistema de astros y de planetas que pueblan la inmensidad de un espacio cuyos límites sólo los conoce el Omnipotente. Ésta, que es una hipótesis en la Física, es una ley necesaria para la conservación de los estados políticos. La tendencia de todos los individuos al centro, esto es la propensión a promover la felicidad pública, no sólo mantiene el orden, no de otro modo que la atracción mutua a cada planeta en su órbita, sino que forma aquel lazo indestructible, aquella indisoluble unidad que requiere toda máquina para que obre los efectos a que está destinada. La base de esta tendencia es el trabajo útil de

paña; el eclecticismo español de los siglos xvii y xvïi, El Colegio de México, México, 1949 , passim; J. Sar RaIll, L'Espagne éclairée de la seconde moitié du xviii ${ }^{\mathrm{e}}$ siècle, Klincksieck, Paris, 1954, esp. pp. 411-469; R. HERR, The eighteenth-century revolution in Spain, Princeton University Press, Princeton, 1958, esp. pp. 154-200; J.M. LóPez PiN̄ERO, La introducción de la ciencia moderna en España, Ariel, Barcelona, 1969; y J. ARCE, La poesía del siglo ilustrado, Alhambra, Madrid, 1981, pp. 292-314.

3 Véase Manuel Morales Borrero, La geometría mística del alma en la literatura española del Siglo de Oro, Universidad Pontificia de Salamanca-Fundación Universitaria Española, Madrid, 1975. 
cada individuo: pero trabajo que debe ser útil en doble sentido, para sí y para el estado ${ }^{4}$.

El lector moderno del pasaje se sorprende al encontrar en Forner la admiración implícita por Newton, pues el primero, como apologista del atraso de España en el campo científico, sentía la necesidad de restar importancia a los nuevos descubrimientos de la época. De todos modos, podemos percibir la confianza que tenía Forner en el mayor peso de las verdades morales por su nota de que sólo Dios Omnipotente tiene la medida del espacio superior; y además, podemos observar que afirma expresamente que la teoría de Newton no es más que una hipótesis, aunque presenta como ley el requerimiento de que el Estado sea el centro de los esfuerzos de todos los ciudadanos ("Newton dijo que la Atracción es la ley. . . Ésta, que es una hipótesis. . .").

Otra línea de desarrollo que ilustra la adaptación del pensamiento matemático o científico a los temas morales parte de dos figuras fundamentales del siglo xvir. Pascal y Descartes abren nuevos caminos para la religión y la metafísica en la época moderna con premisas filosóficas firmemente asentadas en las matemáticas. En los escritos del primero, la síntesis de contrarios, los conceptos de los "dos infinitos" o de los "tres órdenes" tienen una fundamentación matemática ${ }^{5}$. La filosofía de Descartes afirma, sobre la base de nuevos principios, la racionalidad del universo; la razón humana, canalizada por los medios de la matemática y la ciencia, puede explicar todos los fenómenos de nuestra experiencia. A pesar del evidente llamado que hace Descartes a los racionalistas, sus opiniones provocaron fuertes críticas entre algunos philosophes. D'Alembert y Turgot, por ejemplo, le reprochan el no haber demostrado sus principios básicos que, por lo tanto, son de carácter subjetivo. Causa y sustancia seguían siendo conceptos problemáticos, y D’Alembert llegó incluso a condenar el empleo de figuras geométricas en tratados sobre el alma ${ }^{6}$.

A pesar de estas censuras a la extensión de la "geometrización" a la filosofía, se puede encontrar un marco matemático o geométrico en las obras de los pensadores morales menores del siglo xvin. Sin embargo, es de notar que sus tratados a menudo dejan ver tesis secularizadas o heterodoxas. Así, el filósofo escocés Francis Hutcheson desarrolla sus ideas sobre la moralidad de la manera siguiente:

Para encontrar un canon universal que sirva para computar la moralidad de cualesquiera acciones, con todas sus circunstancias, cuando juz-

4 Amor de la patria, Hijos de Hidalgo y González de la Bonilla, Sevilla, 1794, pp. $\mathrm{xix}-\mathrm{xx}$.

5 Véase J.H. Broome, Pascal, Barnes and Noble, New York, 1965, pp. 53-56.

6 Véase Yvon Belaval, "La crise de la géometrisation de l'univers dans la philosophie des Lumières', RIP, 6 (1952), núm. 21, 337-355. 
gamos de las acciones realizadas ya sea por nosotros mismos o por otros, debemos observar los siguientes axiomas o proposiciones:

1) La importancia moral de cualquier agente, o la cantidad de bien público por él producida, es el producto compuesto de su benevolencia y capacidades: o (sustituyendo las palabras por sus letras iniciales, $\mathrm{M}=$ Momento de bien y $\mathrm{u}=$ Momento de mal) $\mathrm{M}=\mathrm{B} \times \mathrm{A}$.

2) De igual manera, el momento de bien o interés privado producido por cualquier persona para sí misma, es el producto compuesto de su amor propio y sus capacidades: o (sustituyendo las letras iniciales) $I=S \times A^{7}$.

Prosigue con esta línea de exposición con perfecta seriedad hasta el punto de representar el amor propio como una fuerza que puede asistir

a la Benevolencia con la fórmula siguiente: " $\mathrm{M}=\overline{\mathrm{B}+\mathrm{S}} \times \mathrm{A}=\mathrm{BA}+\mathrm{SA}$; $\mathrm{y}$ por lo tanto $\mathrm{BA}=\mathrm{M}-\mathrm{SA}=\mathrm{M}-\mathrm{I}$ y $\mathrm{B}=\frac{\mathrm{M}-\mathrm{I}}{\mathrm{A}}$ ', La subordinación de la Benevolencia a ecuaciones matemáticas que plantea Hutcheson elimina efectivamente cualquier sentido de misterio sobrenatural de esta piedra angular de su concepción de la virtud y, en efecto, asevera que no hay necesidad de postular una recompensa divina para las buenas acciones, puesto que hay muchos que son virtuosos sin tener opiniones sobre la divinidad ( $\$ 82$, p. 79).

Un compatriota de Hutcheson, Andrew Michael Ramsay, provocó fuertes sospechas de heterodoxia con su obra en dos tomos, The philosophical principles of natural and revealed religion, unfolded in a geometrical order (Galsgow, 1748-1749). La dificultad esencial que presenta la aceptación de sus teorías radica en su convicción de que "se encuentran vestigios de todas las principales doctrinas de la religión cristiana en los monumentos, escritos o mitologías de todas las naciones, épocas y religiones; y que esos vestigios son emanaciones de la religión primitiva, antigua y universal de toda la humanidad" 8 . Para la exposición de sus ideas sobre la religión natural, Ramsay eligió "un orden geométrico que cier-

7 An inquiry concerning moral Good and Evil (1725), § 126, en L.A. Selby-Bigge (ed.), British moralists, Dover Publications, 1965, t. 1. ("To find a universal Canon to compute the Morality of any Actions, with all their Circumstances, when we judge of the Actions done by our selves, or by others, we must observe the following propositions or axioms. 1) The moral importance of any Agent, or the Quantity of publick Good produc'd by him, is in a compound Ratio of his Benevolence and Abilitys: or [by substituting the initial letters for the Words, as $\mathbf{M}=$ Moment of Good, and $\mathbf{u}=$ Moment of Evil] $\mathbf{M}=\mathrm{B} \times \mathrm{A}$. 2) In like manner, the Moment of private Good, or Interest produc'd by any Person to himself, is in a compound Ratio of his Self-Love and Abilitys: or [substituting the initial Letters] $I=S \times A^{\prime \prime}$, p. 110).

8 " . . . vestiges of all the principal doctrines of the Christian religion are to be found in the monuments, writings or mythologies of all nations, ages, and religions; and that these vestiges are emanations of the primitive, ancient, and universal religion of mankind. . ." (pp. iv-v). 
tamente es la forma más exacta de razonar, la más adecuada para convencer a otros, y para desengañarnos a nosotros mismos" "9.

Podemos inferir de lo anterior que el empleo de términos matemáticos o científicos para expresar ideas en filosofía moral no identifica de manera obvia el tipo de mentalidad del que escribe. Los cristianos devotos favorecen la presencia de esas frases y esos patrones de pensamiento en sus obras, y por lo menos un escéptico critica esa práctica. Las expresiones matemáticas o científicas pueden ser prueba de un punto de vista tradicional y ortodoxo del autor; por otra parte, pueden constituir una mentalidad religiosa menos dogmática o hasta secularizada. Antes de examinar más de cerca los ejemplos españoles de prosa moralista, quisiera hacer una observación general que surge de la comparación de los tecnicismos en la poesía española con los mucho más abundantes materiales de literatura inglesa al alcance de los eruditos ${ }^{10}$. Estos últimos han mostrado que la gran mayoría de los autores ingleses introduce en sus obras referencias a la astronomía, a la física, a la botánica, y especialmente referencias al microscopio y al telescopio, para mostrar de qué manera revelan los nuevos descubrimientos la infinita majestad y la coherente complejidad de la obra divina. La ciencia se vuelve un baluarte en el que se apoya la religión. Aunque las convicciones fuertemente teístas de Newton seguramente ayudaron, los escritores en prosa y verso no trataban el desarrollo científico como el comienzo de una cultura nueva y distintiva, sino como investigaciones que confirmaban la visión tradicional de un orden divino del universo. Pero, si leo correctamente las pruebas aportadas por Arce, los poetas españoles - con las excepción aparente de Trigueros (p. 302) y Meléndez Valdés (pp. 307-309) - exaltaban la revelación de vastos y maravillosos descubrimientos racionalistas. Les importan sobre todo los nombres de los científicos, especialmente Galileo y Newton, y aunque pueden preguntarse sobre el lugar del hombre en este universo expandido, no parecen relacionar la astronomía con la mayor gloria de Dios. Una tendencia semejante está en la base de algunos de los autores que voy a estudiar en las páginas siguientes, pero con mayor frecuencia a medida que el siglo se va acercando a su fin.

El primero de los textos moralistas es especialmente notable porque documenta una de las más tempranas apariciones de la palabra "telescopio", especialmente en una obra no científica" ${ }^{11}$. Antonio Pérez Ra-

9 ". . a geometrical order, which is certainly the most exact way of reasoning the most proper to convince others, and undeceive ourselves"' (p. v).

10 Para una muestra, véase: W. POWELL JONES, "Science in biblical paraphrases in eighteenth-century England", PMLA, 74 (1949), 41-51; The rhetoric of science. A siudy of scientific ideas and imagery in eighteenth-century English poetry, University of California Press, Berkeley-Los Angeles, 1966; y MARJORIE HOPE Nicolson, Science and imagination, Cornell University Press, Ithaca, 1956; The breaking of the circle. Siudies in the effect of the "new science" upon seventeenth-century poetry, Columbia University Press, New York, 1960.

11 Uno de los principales astrónomos de España habría de escribir, en fecha tan tar- 
mírez escribió un tratado sobre la conducta pública que consistía en una larga diatriba contra la envidia, además de varias páginas sobre la integridad requerida en los jueces, y otras cuestiones políticas y sociales. Sin embargo, la base de su instrucción ética no está en la teología sino en una condena más secularizada de la ceguera y la locura humanas. En el pasaje siguiente, el tecnicismo científico de Pérez Ramírez, empleado para realzar una palabra de fuertes asociaciones religiosas, parece especialmente significativo: "Esto es enseñarnos a que no vamos a tientas en nuestras obras, sino a que ojeemos la oportunidad con la preconsiliación, a que expliquemos la providencia (que es el telescopio de los tiempos) y la extendamos hasta aquellos parajes a donde moralmente se puede pronosticar. . ."12

Podemos encontrar el mismo deseo de seguridad y certeza en un campo que es requisito para cualquier hombre que tenga pretensiones de nobleza, a saber, la esgrima. Lo que en una época anterior había sido un arte o una destreza se prestó por vez primera a ser tratado como una ciencia derivada cuando, a mediados del siglo xvII, Luis $\mathrm{Pa}$ checo de Narváez pensó que convenía que el novicio aprendiera geometría, cosmografía y astronomía para familiarizarse con asuntos tales como la línea, la perspectiva, el movimiento y la distancia ${ }^{13}$. Su elaboración de movimientos estratégicos familiares por medio del análisis de las formas geométricas del movimiento de la espada provocó la burla de sus contemporáneos, pero Pacheco representaba una tendencia moderna. Podemos juzgarlo mejor si seguimos el cambio del vocabulario desde el primer tratado de Pacheco, titulado Modo fácil y nuevo para examinarse los maestros en la destreza de las armas (1625), hasta el añadido de "la filosofía y destreza" en el título del segundo tratado. La trayectoria continúa en el siglo XvIII, con la adición de "ciencia" en la obra de Francisco Lorenz y Rada, Nobleza de la espada, cuyo esplendor se expresa en tres libros según ciencia, arte y experiencia (Imprenta Real, Madrid, 1705). Este libro desarrolla el aspecto científico en grabados minuciosamente rotulados que muestran los arcos y los ángulos por medio de los cuales se maneja la espada. Tanto Pacheco como Lorenz de Rada son citados por Juan Claudio Aznar de Polanco en su Arte nuevo de escribir por preceptos 'geométricos y matemáticos (Herederos de Manuel de Murga, Madrid, 1719); quería aplicar el enfoque disciplinado de sus predecesores a su propio arte (fol. $8 \mathrm{r}$ ).

día como 1675, "El largomira o tubo óptico, que todo es uno y vulgarmente se llama anteojo de larga vista", Esfera en común, celeste y terráquea, apud ARMANDO CotaRelo VA. LLEDOR, "El P. José de Zaragoza y la astronomía de su tiempo", en Estudios sobre la ciencia española del siglo xvï, Gráfica Universal, Madrid, 1935, p. 154.

12 Armas contra la fortuna, Antonio Rodríguez Figueroa, Valladolid, 1698, p. 358.

13 Advertencias para la enseñanza de la filosofía y destreza de las armas asi a pie como a caballo, Pamplona, 1642, ff. 160, 171, 175, cit. en D.L. D'OrvenIPE (ed.), Antiguos tratados de esgrima. (Siglo xvii), Vindel, Madrid, 1898. 
El deseo de exactitud, certeza y método se refleja en los ejemplos que acabamos de examinar, pero no es el motivo del lenguaje del autor siguiente. Creo que aquí vemos pruebas de que las disputas entre las distintas escuelas de filosofía natural han aumentado mucho la atención a la ciencia. El problema de la extensión en el espacio da al P. Diego del Castillo, un hombre de formación más bien tradicional, un grupo de metáforas científicas y matemáticas para describir las destructivas rivalidades y divisiones que se dan entre los humanos. El jesuita, sobre la base del "punto de honra", entreteje estas frases en su texto con cierto ingenio:

Fue opinión de algunos filósofos antiguos, a quienes siguen hoy otros modernos, que el cuerpo continuo se compone de puntos hinchados e indivisibles. La más común filosofía con Aristóteles siente que el continuo se compone de partes infinitamente divisibles. Esta controversia se litiga todavía en las Escuelas; y yo hallo que sólo la delicadeza de los hombres vanos ha sido poderosa a concordarla, porque en ellos se hallan los puntos indivisibles e honra muy hinchados, con una interminable división de partes. Vense cada día divididas las familias, ardiéndose en facciones los pueblos, opuestas con implacable furor las naciones, teñidas mutuamente las armas en la sangre de los vecinos. . . Y averiguada la causa de tanta división de partes, comúnmente no es otra sino un punto de honra indivisible, una ofensa tan menuda como un átomo a quien dio cuerpo la hinchazón de los hombres puntosos. Hace en ellos la vanidad lo que el cero en el guarismo, cifra hinchada y hueca, que no teniendo por sí misma valor alguno, es la más opuesta a la unión y no sirve sino de dividir las unidades, haciendo que se multiplique en números infinitos ${ }^{14}$.

Aunque este jesuita todavía se aferra a la física aristotélica, ha absorbido tanto el lenguaje del debate científico del momento que le sugiere un léxico desusado y pegajoso para sus ataques contra la vanidad humana.

Es mucho más comprensible que Benito Jerónimo Feijoo acuda a las matemáticas para hacer más clara su lección sobre la manera en que los humanos dan crédito a ocurrencias extraordinarias ${ }^{15}$. Una mente tan abierta a la nueva ciencia como lo es la suya, y un intelecto que insiste tanto en la claridad y las pruebas firmes podría expresar con naturalidad el problema de la creencia en términos de una regla matemática de probabilidades. Aunque el monje benedictino es único en la España del siglo xvin, no por ello deja de ser plausible que hombres menos grandes que él, con preparación en ingeniería, también enfrentaran diferentes cuestiones morales en términos geométricos. Juan Antonio Pozuelo y Espinosa, producto de una educación militar, escribió

14 Stromas politicos y morales en que. . . se pinta al hombre varonil en su perfección natural, Impr. de la Real Chancillería que es de la Vda. de José de Rueda, Valladolid, 1729, pp. 167-168.

15 "'Regla matemática de la fe humana", Teatro crítico universal, 1732, t. 5; reimpr., $B A E, 142$, pp. $145-160$. 
un libro para la formación del soldado perfecto. Por extraño que pueda parecer, empleó como vehículo literario el género renacentista de la empresa, pero terminó cada uno de sus cincuentaicinco capítulos con una representación geométrica de la lección moral ${ }^{16}$. Podemos tener un ejemplo de su enfoque viendo cómo llama al joven soldado a expresar su devoción religiosa por medio de actos heroicos. El reto es crear un triángulo equilátero en una recta dada, y atender al mismo tiempo al valor moral que atribuye Pozuelo a cada paso (pp. 24-25). Para hacerlo, se trazan primero dos círculos en puntos separados de la línea, de tal manera que se traslapen; el triángulo se puede trazar dentro del área circunscrita por la intersección de las circunferencias. Ahora bien, un círculo denota que toda la superficie redonda de la tierra rinde homenaje a Dios; el segundo círculo, según Pozuelo y Espinosa, representa los sacrificios y ofrendas del heroico corazón del soldado. El hecho de que las circunferencias de los dos círculos no se fundan transmite la lección de que el soldado, al cumplir esta virtuosa empresa, no debe ir a los extremos de la temeridad.

Nadie puede tomar en serio hoy en día la exposición de Pozuelo y Espinosa; su aplicación de valores morales a las formas geométricas es ingenua y torpe a la vez. Sin embargo, no podemos dejar de notar su deseo de transferir, en su afán de enseñanza, la claridad y la forma directa de operación de un campo al otro. Hay peligro de distorsión al tratar de hacerlo; pero lo que es más, como nos dice un moralista italiano traducido al español, no hay necesidad de hacerlo. También se pueden discutir las virtudes en un lenguaje preciso. Jacinto Dragoneti acaba de marcar el contraste entre la satisfacción de los europeos que tienen acceso fácil a sus gobernantes y la supuesta severidad de ciertas comunidades bárbaras que no toleran un gobernante abierto y amable. A continuación dice: "Siendo constantes estas diferencias, la Geometría, que funda sus demostraciones sobre principios sólidos y ciertos, no podía nunca demostrarnos la verdadera graduación de las virtudes; y a la infalibilidad del cálculo matemático sería necesario substituir lo sumo de la exactitud moral"' ${ }^{17}$. Las objeciones de Dragoneti ponen de relieve el movimiento del pensamiento que en su época ya era obvio. Las incursiones en la terminología geométrica o matemática estaban diseñadas para reducir la falta de inteligibilidad o la abstracción de los tratados moralistas y para volver posible en asuntos religiosos la cualidad de la certeza demostrable. Al mismo tiempo la tendencia expone, aunque en forma indirecta, el surgimiento de una cultura separada que rivaliza con los valores cristianos tradicionales.

16 Empresas políticas militares, que con el adorno de moralidades y virtudes tienen por único y principal objeto sacar un perfectísimo soldado, José González, Madrid, 1731.

17 Tratado de las virtudes y de los premios, trad. de Francisco de Hombrados Malo, Antonio de Sancha, Madrid, 1775, p. 22. El libro fue condenado por la Inquisición; véase Antonio Rodríguez Moñino, La imprenta de don Antonio de Sancha, Castalia, Madrid, 1971, pp. 88-89. 
En ningún campo es esto más evidente, en la España del siglo xviII, que en la nueva disciplina de la política económica. Lo que buscaban ahora aquellos que se ocupaban de los asuntos públicos era la experiencia técnica, pues aunque el empleo de medios virtuosos para lograr las finalidades morales de la política era un principio que no se cuestionaba, ya no era suficiente como guía práctica. Basta con leer las siguientes palabras de Pedro Rodríguez Campomanes para ver lo profundas que eran las raíces que tenía en su mente esa cultura matemático-científica:

Son muy pocos en todas las edades y naciones los que pueden tratar estas materias económicas con la instrucción y solidez necesarias hasta que la discusión literaria manifesta los caminos más seguros. Dicta pues la buena crítica recoger los tratados que se hayan escrito; meditarlos y formar de ellos un sistema político y constante para presentar a la nación metódicamente sus verdaderos intereses, evitando equivocaciones sistemáticas cuanto fuere posible. .

Declamar contra semejante estudio sería lo mismo que aspirar a apagar la luz y declarar la guerra al celo público. El barómetro para conocer la educación e instrucción de un país debe tomarse de la prosperidad que saben procurarse sus habitantes. .

Sin escritores y arismética política, ninguna nación llega a conocer bien sus intereses. . . ${ }^{18}$

Debe quedar claro que la "arismética política" que quiere instituir Campomanes es la parte esencial de su programa; pero las claves para entender su tipo de pensamiento se encuentran en palabras como solidez, caminos más seguros, un sistema político, metódicamente, el barómetro. La administración pública debía ser una disciplina científica, y aquellos que siguen la dirección de Campomanes aclaran aún más cuánto se ha avanzado, en esta forma de pensar, respecto a los tratados de una época anterior sobre el buen príncipe:

La ciencia de los cálculos es útil no solamente en los grandes negocios generales sino también en los subalternos de la administración. Sus luces enseñarán a cualquiera a gobernar bien las fuerzas y facultades de los pueblos que se le han confiado; y una vez acostumbrados a razonar por números, tendrán la ventaja de cometer pocos yerros en las relaciones que presenten a la superioridad de las rentas y del comercio del estado ${ }^{19}$.

Las líneas anteriores revelan la completa confianza de su autor en la posibilidad de un gobierno ordenado por las matemáticas, y que funcione virtualmente sin errores.

18 Apéndice a la educación popular. Parte Primera, Antonio de Sancha, Madrid, 1775, pp. xxvii-xxix.

19 Nicolás de Arriquibar, Recreación política, Tomás de Robles y Navarro, Vitoria, 1779 , t. 1 , pp. 10-11. 
La utilidad y la iluminación serán frutos de un régimen de cálculo, pero no sólo en la economía política. Seguramente que esta mentalidad progresiva y rigurosamente metódica también debe tener su efecto en el estilo de la prosa ${ }^{20}$. El tema necesita un estudio mucho más largo del que es posible hacer aquí, pero un pasaje de una obra importante de Antonio Arteta y Monteseguro señala la dirección que debería seguir un estilo de prosa más racional. Hace notar que sólo las ciencias y las artes útiles son estimadas en su época, porque ofrecen el único método ventajoso para el progreso del conocimiento humano. Entonces, a media frase, Arteta pasa al estilo de escritura requerido: "aquel método, digo, que junta la claridad a la precisión, que no se sirve de términos técnicos y científicos sino en cuanto la materia lo exige absolutamente. Se procuran ya exponer los principios de las ciencias con toda claridad posible a fin de hacer la inteligencia más general y facilitar la aplicación de estos principios a las artes útiles" ${ }^{21}$. Quiere rechazar cualquier cosa que suene a jerga, a menos que sea absolutamente necesaria; como muchas personas deben aprender estas ideas útiles, se deben expresar con claridad y precisión. Explica además que è campo de la química ilustra lo que quiere decir. Ha sido una ciencia de oscuridad impenetrable, y su aire de magia extraña fue fomentado por un lenguaje que pocos podían entender. Sin embargo, Hermann Boerhaave rescató a la química de su oscuridad, y logró "exponer sus principios y manipulaciones de una manera inteligible a todo hombre de buen sentido".

Lo distintivo de esta prosa científica o más objetiva surge del contraste que presentan las observaciones del colaborador anónimo de una columna regular del Correo de Madrid, "Ocios filosóficos"'. El autor se distancia de la admiración que siente la época por el progreso científico. Los investigadores modernos, segun él, tratan de rebasar los límites de la razón humana, pues la Madre Naturaleza es la que "podrá hablarte con un lenguaje cierto y eficaz". No engañará a sus lectores actuales, pero aunque estos se equivoquen, sus predecesores aclararán las dudas. Este autor que mira hacia el pasado declara que la filosofía moderna trata de destruir los firmes principios de la religión. Lo que debería intentar un investigador cristiano es "profundizar todas las materias para hacer conocer las que tienen estrecha relación con la virtud,. . . ensalzarla y elevarla al último punto de que es capaz la elocuencia y la solidez de unos buenos principios" ${ }^{22}$. Con la adición de una retórica y una elocuencia persuasivas en favor de una finalidad moral, el es-

20 Richard F. JONEs da excelentes ejemplos, incluyendo un extracto especialmente revelador de la History of the Royal society (1667), de Thomas Sprat, sobre las reformas retóricas que buscaban los científicos británicos; véase su "Science and English prose style in the third quarter of the seventeenth century", PMLA, 45 (1930), 977-1009, esp. pp. 986-987.

21 Disertación sobre el aprecio y estimación que se debe hacer de las artes prácticas, Blas Miedes, Zaragoza, 1781, pp. 78-79.

22 Correo de Madrid, 6 (1789), pp. 2581-2582. 
critor conservador y religioso cultiva un estilo de prosa que es sustantivamente diferente del que busca Areta y Monteseguro.

De hecho, los aspectos progresistas y modernos de la ciencia atraían a grandes cantidades de personas. Las ciencias llegaron a ser tema de conversación en los salones de todos aquellos que se creían inteligentes y querían brillar en sociedad. Tan extendida estaba el habla científica que un supuesto corresponsal de un periódico madrileño se quejaba, con ironía, de que los ricos y los nobles habían abandonado sus frívolas costumbres de otros años. "Los convidados que frecuentan tu mesa son tan impolíticos que jamás hablan de cómicas, nunca comprometen el honor de mujer alguna, ni se les ha oído elogiarte. ¿Qué podrán ser tales hombres sino unos espíritus geométricos que aplican la regla y el compás a las palabras y alabanzas?"'23

José Marchena confirma indirectamente la amplia asimilación de las ideas científicas al utilizar palabras técnicas de la química para nada menos que la crítica literaria. En el último artículo que escribió para su efímero periódico, nos da el siguiente delicioso informe de una de sus "experiencias" de laboratorio:

Ha muy poco tiempo que di en aplicarme algo a la química, y he compuesto, como Dios me ha ayudado, mi pequeño laboratorio en el que he comenzado a hacer algunas experiencias. He procurado extraer las substancias salinas de muchas sátiras y el flogisto de muchas poesías; pero los resultados de mis descomposiciones han sido muy diferentes de lo que yo pensaba. Muchas se han reducido a tierra o capul mortuum, y algunas se han desvanecido todas en aire. La Oración apologética del señor Forner se ha reducido a la primera de estas materias, y los Discursos filosóficos a la segunda. Los discursos del "Apologista universal" [o sea, Fr. Pedro Centeno y Joaquín Ezquerra] se han convertido todos en substancias salinas, pero las sátiras de Huerta se han reducido todas a ácido nitroso, y el espíritu de sus obras a gas inflamable. Noté que algunas de las obras que sometía al examen tenían la propiedad de convertir el oro más acendrado en plomo. . . Muchas obras teológicas eran puro aire, pero impregnado de partículas mefíticas que mataban todo lo que tocaban ${ }^{24}$.

Marchena pasa luego a bendecir la inspiración que lo llevó a construir su laboratorio, y concluye con un catálogo de obras que, al ser analizadas, revelaron que su materia básica eran gases dañinos, ácidos, plomo, flogisto, y así sucesivamente.

Clemente Peñalosa y Zúñiga, defensor del absolutismo, advierte en

23 “'Carta 15”, El Corresponsal del Censor, Madrid, 1787, p. 240. Paul-J. Guinard hace notar la proposición anterior de Emilio Cotarelo, según la cual el autor es Santos Manuel Rubín de Celis (La presse espagnole de 1737 à 1791, Institut d'Études Hipaniques, Paris, 1973, p. 325, nota 1).

24 "Discurso sexto", El Observador (s.p., s.f. [1787]), pp. 81-83. Para la atribución de esta publicación periódica a Marchena, véase Guinard, p. 333. 
contra de los que aplican el método científico a los campos de la filosofia moral, "ansiosos de sujetar todo principio divino, natural y político a la fuerza escrupulosa de la demostración".25. Peñalosa muestra algo de su moderación al admitir escrúpulos por lo menos para el método demostrativo. Como no es ni un partidario ciego de los escolásticos, ni un abogado incondicional de la precisión matemática en el estudio de los asuntos humanos, lanza una advertencia contra los charlatanes que hacen daño a estudios como el de la jurisprudencia al tener excesivas pretensiones para su enfoque geométrico (p. 7). Sin embargo, Peñalosa y Zúñiga, en otro libro, emplea una analogía con los químicos analíticos modernos para refutar los argumentos de los críticos modernos del heroísmo militar ${ }^{26}$. Más adelante, en la misma obra, hace la comparación siguiente con el amor propio como motivador de actos elevados: "Así los químicos animan con sales acres y corrosivas ciertas drogas para que presten todo su vigor"' (p. 33).

El descubrimiento de la vacuna contra la viruela por Edward Jenner provocó una polémica mayor entre los profesionales y maestros de la medicina. Inevitablemente, el gran interés engendrado en círculos profesionales y no profesionales llevó a la generalización de lo que había sido un vocabulario técnico restringido. Un ejemplo notable de esto es la publicación en Francia, en 1761, de un panfleto, $L$ 'inoculation du unn sens, que intentaba inyectar figurativamente en las mentes de los franceses la buena manera de pensar que terminaría con la frivolidad y la superficialidad de la vida pública. El panfleto fue traducido al español, con el título de Inoculación al buen juicio, pero quedó en manuscrito. Sin embargo, en 1789 Cecilio Pérez publicó su imitación del original francés para crear dirigentes capaces de remediar las enfermedades específicas que aquejaban a ios españoles ${ }^{27}$. Declara en su introducción que, a pesar de la crítica y las burlas que le habrán de dirigir los adversarios de la vacunación, ha perseverado tanto en su promoción de la ciencia como en sus críticas de la vida española, por el bien de su país.

El patriotismo también es el estímulo que mueve una de las inteligencias españolas más ilustradas de fines del siglo Xvir, la de Valentín de Foronda; y claro que la preocupación por la ciencia y la tecnología es uno de los rasgos constantes de su obra. Por ejemplo, su Miscelánea

25 La monarquía, Vda. de Ibarra, Madrid, 1793, p. 6. Véase Javier Herrero, Los orígenes del pensamiento reaccionario español, Edicusa, Madrid, 1971, pp. 128-131.

26 El honor militar, Benito Cano, Madrid, 1795, p. 8.

27 La inoculación del entendimiento, Benito Gano, Madrid, 1789. Véase también JeAN SeZnec, "L'inoculation du bon sens (Londres et Oxford)", Essays on Diderot and the enlightenment in honor of Otis Fellows, ed. John Pappas, Droz, Genève, 1974, pp. 286-291; y GUY MERCADIER, "Une traduction espagnole inédite de $L$ 'inoculation du bon sens (1761)", en Mélanges offerts à Charles Vincent Aubrun, ed. Haïm Vidal Sephiha, Éditions Hispaniques, Paris, 1975, t. 2, 31-42. JOAQuín ARCE llama la atención hacia sus escritos anteriores sobre la inoculación y la vacunación en la poesía española (op. cit., pp. 102-103). 
o colección de varios discursos incluye un ensayo sobre la necesidad de corregir errores de física, química y matemáticas cometidos por Feijoo. Pero su asimilación de la cultura científica contemporánea se manifiesta, más que en temas específicos, en el frecuente uso que hace de la terminología característica. Al hablar de la correlación entre la intensificación del comercio y el crecimiento de la población en otro ensayo, Foronda escribe: "Pero qué más prueba de que el tráfico atrae a la población en razón directa de su masa hablando en el idioma de los Newtones. . ."28 Es especialmente significativa su creación de "Newtones" porque muestra con tanta claridad que para esa época el gran inglés ya se había convertido en una categoría abstracta y, más que ser un individuo con teorías específicas, simbolizaba un punto de vista.

Foronda emplea la invención del pararrayos para comunicar su deseo de que el prólogo de otro libro absorba, como el nuevo artefacto, los relámpagos del prejuicio, la envidia y el odio que probablemente atraiga la obra ${ }^{29}$. Como antiguo residente de la ciudad de Filadelfia, no es de sorprender que conozca bien las ideas del inventor, y quiere mostrarlo: "así como el gran Franklin decía que esperaría debajo de una campana de cristal todos los rayos que se formasen en una nube borrascosa. Este célebre sabio decía muy bien porque conocía que resguardándose con un cuerpo que no es electrizable por comunicación sino por frotación, no podía transmitirse a él una porción de electricidad que lo redujera a ceniza" (página sin número).

Claro que ésa es una disquisición bastante complicada para algo que sólo es una sencilla comparación en un prólogo, pero atestigua la devoción científica del autor. La ciencia es tan parte de su pensamiento que parece ser atraído de manera casi irresistible por esas metáforas. En un ensayo sobre la educación, para dar otro ejemplo, Foronda habla de la incapacidad de los gobiernos para crear personas útiles y benéficas; y, como si fuera la secuencia de ideas más natural y evidente, escribe: "Un químico jamás sacará de un alma baja, de un alma apática, de un alma oprimida sino vilezas, timidez, y aquel qué se me da a mí, neutralizante de las acciones útiles a la sociedad en que uno vive"'30.

Foronda estaba consciente de lo que hacía. En un pasaje extremadamente revelador, que citaré con cierta extensión, observa en tono defensivo:

\footnotetext{
28 "Lo honrosa que es la profesión del comercio", Miscelánea o colección de varios discursos, Benito Cano, Madrid, 1787, p. 8; el subrayado es suyo.

29 "Prefacio", Cartas sobre los asuntos más exquisitos de la economía política y sobre las leyes criminales, Manuel González, Madrid, 1789, s.p. Sobre su estancia en América, véase JefFerson Rea SPell, "An illustrious Spaniard in Philadelphia - Valentín de Foronda', HR, 4 (1936), 136-140; y José DE ONís, "Don Valentín de Foronda en los Estados Unidos", CuH, 69 (1967), 448-464.

30 "Carta VII: sobre los efectos productores de la educación [1800]", Cartas sobre la policia, Ramón Domingo, Pamplona, 1820, p. 5. La primera edición apareció en 1801.
} 
También han advertido [algunos de mis lectores] que uso frecuentemente de comparaciones científicas, como lo hago en esta carta, lo que han desaprobado con todo su corazón. En este punto no pienso darles gusto, pues cada uno habla como sabe, y yo no sé hacerlo de otro modo. Tal vez no faltará quien crea que las empleo por una especie de afectación físicamatemática, lo que me trae a la memoria una especie de Feijoo quien dice, hablando de estilos, "que calificamos de afectación aquel lenguaje que no nos es natural". Bien sabido es que el carpintero se vale de comparaciones y alusiones de su oficio cuando se explica; que el pintor y el teólogo hacen lo mismo. Así, aunque no soy matemático, químico, ni físico de profesión, como ha hecho mis delicias por varios años el estudio de las ciencias naturales y exactas, les he cobrado cierto cariño que manifiesto sin libertad siempre que hablo. Y este vicio, si lo es, me lo han consolidado estos sabios y filósofos caballeros Vergareses [es decir, la Sociedad Bascongada de los Amigos del País] entre quienes son tan familiares las ciencias indicadas que hablan de ellas en la tertulia y en el paseo como se pudiera hacer en una academia. De aquí resulta que aun la conversación festiva se resiente de la afición dominante, sin que nadie ponga mala cara porque uno se valga en sus alusiones y comparaciones de la química, de la física, o de las matemáticas ${ }^{31}$.

Foronda rechaza la posible acusación de afectación asegurando no sólo que toma los términos científicos con tanta naturalidad como lo haría cualquier otro con los de sus actividades laborales normales, sino también que su uso va de acuerdo con su habla ordinaria. El pasaje citado es especialmente valioso como testimonio de que los temas científicos eran habituales y vitales en la conversación de los intelectuales de provincia.

Sin duda que quienes reciben y fomentan esta cultura científica y matemática en el siglo xvin no pertenecen a la generalidad del pueblo español, pero sí forman parte de círculos significativos en muchas ciudades del país. Entre esos grupos ha surgido una mentalidad que parece aceptar la adquisición del conocimiento científico y filosófico como marca de virtud y distinción. Según esta forma de pensamiento, el heroísmo ya no está limitado al constructo tradicional de grandes figuras militares o políticas, sino que ahora se puede extender a los poetas y a los eruditos. Anticipándose a las conferencias de Carlyle en el siglo siguiente, un colaborador no identificado del Correo de Madrid, a fines del siglo, presenta esos argumentos elogiando especialmente la forma en que la imprenta ha hecho posible que las obras de los grandes sabios tengan influencia en lectores de bibliotecas remotas y épocas lejanas. Son notables entre sus ejemplos del sabio como héroe los nombres de Bayle, Descartes, Gassendi y Locke ${ }^{32}$. De lo anterior debería quedar

31 "Sobre la utilidad de los buenos caminos y de los canales [1789]", Cartas sobre los asuntos. ..., Manuel González, Madrid, 1794, t. 2, pp. 50-51.

32 "Ocios filosóficos", Correo de Madrid, 6 (1790), p. 2589. 
claro que esos grandes pensadores no sólo son modelos para disciplinas académicas específicas, sino para una cultura filosófica y científica de base más amplia, establecida firmemente en España al comienzo del siglo XIX.

Monroe Z. Hafter

University of Michigan.

Traducción de Flora Botton-Burlá. 